\title{
Engine Combustion Network (ECN): Global sensitivity analysis of Spray A for different combustion vessels
}

\author{
Yuanjiang Pei ${ }^{\mathrm{a}, *}$, Michael J. Davis ${ }^{\mathrm{b}}$, Lyle M. Pickett ${ }^{\mathrm{c}}$, Sibendu Som ${ }^{\mathrm{a}}$ \\ ${ }^{a}$ Transportation Technology Research and Development Center \\ Argonne National Laboratory, Argonne, IL 60439, USA \\ ${ }^{b}$ Chemical Sciences and Engineering Division \\ Argonne National Laboratory, Argonne, IL 60439, USA \\ ${ }^{c}$ Combustion Research Facility \\ Sandia National Laboratory, Livermore, CA 94550, USA
}

\begin{abstract}
Global sensitivity analysis was conducted on Spray A of the Engine Combustion Network's (ECN) experimental conditions across different combustion vessels from different institutions. The main objective was to understand the influence of differences in boundary conditions on specific targets of interest. A list of experimental initial, boundary, and injection conditions with uncertainty ranges were identified for three different ambient conditions for these combustion vessels. Five targets including the liquid length, vapor penetration length, ignition delay, lift-off length, and soot mass in the domain were extracted from hundreds of 3D computational fluid dynamics (CFD) simulations by simultaneously perturbing all the uncertain variables. Each target was analyzed using a global sensitivity analysis (GSA) method and the relative importance of different variables towards specific targets was identified. The uncertainty in the fuel temperature was found to have a profound
\end{abstract}

\footnotetext{
${ }^{*}$ Corresponding author, Phone number: +1 (630) 252-5237

Email address: ypei@anl.gov (Yuanjiang Pei)
} 
influence on the liquid length, however, the influence on vapor penetration length, ignition delay, and lift-off length, was rather subtle. Small uncertainties in the initial turbulence level and nozzle diameter was observed to have a significant influence on the vapor penetration. Variables sensitive to ignition delay also showed similar sensitivity to flame lift-off length. The soot mass in the domain was observed to have a closer correlation with the liquid length at least for higher ambient temperature conditions.

Keywords:

Spray A, representative interactive flamelet, Engine Combustion Network, diesel, global sensitivity analysis, n-dodecane 


\section{Introduction}

Fuel economy, emission requirements, and natural resource pressures are driving the need for more efficient engines. Researchers worldwide are striving to improve the predictive ability of the simulation tools involved in designing these engines. Several experimental groups envisage providing highfidelity experimental data for validation of the simulation tools. Towards this goal, the Engine Combustion Network (ECN) provides an international platform involving many research institutions and industries worldwide to make available high-quality experimental data under well-defined boundary conditions applicable to engine combustion [1]. An n-dodecane spray flame called

Spray A has been the focus of both experimentalists [2-5] and modelers [614] in ECN. Although n-dodecane is not an ideal surrogate for transportation fuels, its choice is driven by the fact that the surrogate lends itself to different optical measurements and the physical and chemical properties of the fuel are precisely defined, unlike pump fuels. All facilities interested in contributing to ECN were requested to provide spray and combustion measurements under identical ambient, boundary, and injection conditions.

Despite the goal for "identical" experimental conditions across the institutions, there were differences between these facilities, some of which are unavoidable because of the unique characteristics of chambers operating at high-pressure and temperature (60 bar and $900 \mathrm{~K})$. The experimental groups are seeking to understand and quantify the differences/uncertainties in detail, and they are standardizing experimental practices for the comparison of different spray metrics $[15,16]$. Some variances in boundary conditions do not seem to affect spray combustion significantly, but this depends upon the 
quantity of comparison. For example, Spray A experiments from different facilities suggested relatively good agreement for ignition delay and lift-off length, despite some variations in ambient compositions, injector geometry, and measurement techniques [17]. Another study in the same combustion chamber revealed that there were significant differences in the measured liquid length $(\sim 17 \%)$ for a set of Spray A injectors with the same design specifications, suggesting that manufacturing tolerances for each injector are important. However, smaller differences were observed for other targets of interest, such as vapor penetration length, ignition delay and lift-off length. [18]. Understanding what physical boundary conditions are most important for engine spray combustion is important to improve combustion performance, and to make modeling tools more predictive in finding optimums.

In simulations, the boundary conditions are exact; thus, the results are more appropriate for uncertainty quantification analysis. Together with the uncertainty quantification techniques $[19,20]$, the uncertainties can be quantified to help understand the differences between different combustion facilities and enable better standardization of spray conditions. For example, researchers could look into the details of the ambient composition and use the exact same composition in combustion vessels, provided that the ambient composition is observed to be very sensitive to the targets of interest.

To estimate the influence of the input uncertainties on certain targets of interest, sensitivity analysis can be used. The global sensitivity analysis (GSA) method is a technique for uncertainty quantification widely used in the chemical kinetic community. These GSA studies have identified the important reactions in large chemical kinetic mechanisms which influence a 
particular target such as ignition delay [20-22]. Local sensitivity analysis is not very insightful in this regard, especially for large chemical mechanisms. The GSA method has several advantages over traditional local sensitivity analysis since: i) it provides a more realistic picture as it simultaneously incorporates the uncertainty information for all the relevant parameters considered, ii) it addresses important parameters where the response of the targets to the values of the variables is highly non-linear, and iii) interactions between different parameters are included.

Global sensitivity analysis was applied to engine simulation for the first time by Pei et al. [19] to quantify the sensitivities of various inputs such as experimental boundary conditions, fuel properties, and modeling constants. One hundred high-fidelity 3D simulations were performed and the influence of the uncertainty in input variables on multi-target functions such as ignition delay, combustion phasing, and emissions were reported. This study showed that the GSA method can provide promising and insightful results regarding the influence of various uncertainties on a diesel engine simulation.

The main objective of this study is to use the GSA method to quantify the uncertainties for Spray A, and to identify the most sensitive boundary conditions and variables affecting different spray and combustion targets. This will aid in understanding the variations of conditions between different facilities and their influence on targets of interest. It will also provide direction on which boundary conditions require the highest level of control, in order to standardize experiments in different combustion vessels. 


\section{Methodology}

\subsection{Combustion vessels review}

Two different types of combustion vessels have been used to conduct the Spray A experiments, constant-volume preburn (CVP) $[2,3]$ and constantpressure flow (CPF) $[4,5]$ rigs. Sandia National Laboratory (SNL), Institut Francais du Petrole - Energies Nouvelles (IFPEN), and the Technical University of Eindhoven (TU/e) use the CVP vessel. These vessels achieve the target experimental conditions by igniting a pre-filled diluted combustible mixture and letting the hot products cool down for a relatively long period ( $\sim$ seconds) in order to reach the desired conditions. The Universitat Politècnica de València - CMT-Motores Térmicos (CMT) and Caterpillar, Inc. use the CPF facility. To achieve the desired experimental conditions, the gas is pre-heated to target conditions as it flows past a cooled injector mounted in a test rig. Detailed information describing these facilities can be found in references $[15,16]$.

The nominal experimental conditions for Spray A are listed in Table 1. Three baseline cases with varying initial temperatures considered in this study are also shown in the table.

\subsection{Uncertain variables}

A list of experimental variables and their variances between facilities considered in this study are shown in Table 2. The variances include measured quantities for boundary and initial conditions, injection parameters, and fuel properties, in addition to uncertainty in the measured quantity, as detailed in

references $[1,15,16]$. The variance has actually been reduced significantly by 
Table 1: Experimental nominal boundary conditions

$\begin{array}{ll}\text { Fuel temperature }(\mathrm{K}) & 363 \\ \text { Nominal nozzle-hole diameter }(\mathrm{mm}) & 0.09 \\ \text { Common-rail pressure }(\mathrm{MPa}) & 150 \\ \text { Ambient density }\left(\mathrm{kg} / \mathrm{m}^{3}\right) & 22.8 \\ \text { Ambient } \mathrm{O}_{2}(\%) & 15^{a} \\ \text { Ambient temperature }(\mathrm{K}) & 800 / 900 / 1100 \\ \text { Ambient pressure }(\mathrm{MPa}) & 5.25 / 5.94 / 7.3\end{array}$

${ }^{\text {a }}$ Mole fraction.

a detailed comparison of methods and results from different facilities, but significant scatter remains. Together these variances constitute the uncertainty in boundary conditions from these spray chambers for CFD calculations.

The wall temperatures of the combustion vessels are different between the vessels and do not reflect the temperature of the ambient gases. The vessel body temperature is around $470 \mathrm{~K}$ and the cooled injector port can reach 400 $\mathrm{K}$ for the CVP vessels, while the wall temperature for the CPF rigs is around $800 \mathrm{~K}$ except at the cooled injector port. The Spray A initial gas velocity is specified to low, near-quiescent values $(<1 \mathrm{~m} / \mathrm{s})$ in comparison to a 600 $\mathrm{m} / \mathrm{s}$ spray velocity. Gas velocity measurements prior to injection have been performed, but there is no complete measurement for the initial turbulence levels for the gas flow-field in the vessels. Some differences in the flow-field are known because of different mixing fan speeds or cross-flow velocity pattern. Particle tracking velocity measurements show $0.1 \mathrm{~m} / \mathrm{s}$ fluctuation for the SNL CVP vessel, while the measured mean velocity is $1 \mathrm{~m} / \mathrm{s}$ for the IFPEN 
Table 2: Variables and their uncertainty ranges for the $900 \mathrm{~K}$ ambient temperature condition.

\begin{tabular}{|c|c|c|c|c|}
\hline & Parameters & Abbreviation & Minimum & Maximum \\
\hline \multirow[t]{8}{*}{ Boundaries } & Vessel wall temerature (K) & $\mathrm{T}_{\text {wall }}$ & 400 & 800 \\
\hline & Initial gas velocity fluctuation $(\mathrm{m} / \mathrm{s})$ & Vel $_{i n i t}$ & 0.01 & 1 \\
\hline & Ambient temperature $(\mathrm{K})$ & $\mathrm{T}_{a m b}$ & 887.5 & 915.1 \\
\hline & Ambient pressure $(\mathrm{MPa})$ & $\mathrm{P}_{a m b}$ & 5.91 & 6.09 \\
\hline & Ambient $\mathrm{O}_{2}(\%)$ & $\mathrm{O}_{2, a m b}$ & 14.9 & 15.1 \\
\hline & Ambient $\mathrm{OH}(\mathrm{ppb})$ & $\mathrm{OH}$ & 0 & 16 \\
\hline & Ambient $\mathrm{CO}_{2}(\%)$ & $\mathrm{CO}_{2}$ & 0 & 6.4 \\
\hline & Ambient $\mathrm{H}_{2} \mathrm{O}(\%)$ & $\mathrm{H}_{2} \mathrm{O}$ & 0 & 11.6 \\
\hline \multirow[t]{4}{*}{ Injection } & Duration of injection (ms) & DOI & 1.49 & 1.65 \\
\hline & Fuel temperature $(\mathrm{K})$ & $\mathrm{T}_{\text {fuel }}$ & 343 & 403 \\
\hline & Discharge coefficient & $\mathrm{C}_{d}$ & 0.88 & 0.92 \\
\hline & Nozzle diameter $(\mu m)$ & $\mathrm{D}_{\text {nozzle }}$ & 83.7 & 90.8 \\
\hline \multirow[t]{5}{*}{ Fuel properties } & Critical temperature $(\mathrm{K})$ & $\mathrm{T}_{\text {crit }}$ & 645 & 659 \\
\hline & Density $^{b}$ & $\rho_{\text {fuel }}$ & 0.98 & 1.02 \\
\hline & Heat of vaporization ${ }^{b}$ & $\Delta H_{v a p}$ & 0.98 & 1.02 \\
\hline & Vapor pressure $^{b}$ & $\mathrm{P}_{\text {vapor }}$ & 0.98 & 1.02 \\
\hline & Viscosity $^{b}$ & Visc & 0.98 & 1.02 \\
\hline
\end{tabular}

${ }^{b}$ Normalized by the baseline temperature-dependent values.

CVP vessel [2]. The gas velocities in CPF facilities are also measured to be around $0.1 \mathrm{~m} / \mathrm{s}$. However, order of magnitude variations are expected in this parameter, and to account for these variations, an initial gas velocity fluctuation upper limit of $1 \mathrm{~m} / \mathrm{s}$ is deemed reasonable. 
The ambient compositions listed in the table target a specification of $15 \%$ oxygen, but there are inherent differences in the balance of major and minor species composition if a preburn or flow vessel is utilized. Preburn composition varies because the initial reactant concentration can be varied between facilities, and flow vessels have chosen to use dry air diluted with only pure nitrogen. Note that in Table 2, units are in mole fraction units , but because of the different major species, the percentage of oxygen will change when presented in mass-fraction units. For example, the ambient $\mathrm{O}_{2}$ is $15 \%$ with a variation of $\pm 0.1 \%$ in mole fraction, however, the mass fraction ranges from $16.4-17.5 \%$, considering different vessels. In terms of the minor species, only $\mathrm{OH}$ is considered in this study, and the values were approximated from chemical kinetics calculations given in references [15, 23]. The mass flow rate of injection is affected by several parameters in addition to injection pressure, which in turn affects key spray and combustion targets. The injection parameters were integrated using Equation 1, with the injection pressure held constant at around $150 \mathrm{MPa}$.

$$
\dot{m}_{f}=C_{d} A_{f} \rho_{f} \sqrt{\frac{2 P_{i n j}}{\rho_{f}}}
$$

where $\dot{m}_{f}$ is the fuel mass flow rate, $\mathrm{A}_{f}$ is the injector exit area, and $\mathrm{P}_{i n j}$ is the injection pressure. The uncertainty of the fuel temperature in Table 2 is caused by several factors inherent in sustaining a major difference between the gas $(900 \mathrm{~K})$ and fuel $(363 \mathrm{~K})$. The fuel temperature is inferred from the fact that measurements show that the injector tip was heated up to about $403 \mathrm{~K}$ during the preburn process for the CVP vessels, while the upstream fuel temperature (upstream of the needle valve) was $343 \mathrm{~K}$. Measurements 
also show an increasing liquid length with time, suggesting the actual fuel temperature cools with time after the start of injection. In addition, many simulations that employed compressible flow treatment of the fuel report a significant drop in fuel temperature while flowing though the injector orifice [24]. The uncertainty ranges of the fuel thermodynamic properties for ndodecane were obtained from reference [25].

For the ambient temperatures of $800 \mathrm{~K}$ and $1100 \mathrm{~K}$, the vessel wall temperature, ambient temperature and pressure are scaled based on the uncertainty ranges at $900 \mathrm{~K}$, while all other variables and their ranges are kept the same.

\subsection{GSA methodology}

GSA is used to explore the relations between the input parameters and the outputs or the targets of a model. The GSA approach is significantly different from a local sensitivity analysis approach [26] where typically, only one parameter is varied. Hence, the relative sensitivity of different variables on targets of interest cannot be captured in local sensitivity analysis.

Details of the GSA methodology can be found in Ref. [27] but a brief description is provided here. Assume that there are ' $N$ ' number of parameters and each of them are equally likely to lie anywhere within the uncertainty range as shown below:

$$
v_{i} \in\left[\begin{array}{ll}
v_{i}^{L} & v_{i}^{H}
\end{array}\right], i=1,2, \ldots, N,
$$

where $v_{i}$ represents the $i^{\text {th }}$ variable, $v_{i}^{L}$ and $v_{i}^{H}$ are the lower and high limit of its uncertainty, respectively. The probability distribution of the $N$ parameters is assumed to be uniform within the $N$-dimensional uncertainty 
hypercube [20]:

$$
\Omega=\left[\begin{array}{ll}
v_{1}^{L} & v_{1}^{H}
\end{array}\right] \otimes \ldots \otimes\left[\begin{array}{ll}
v_{i}^{L} & v_{i}^{H}
\end{array}\right] \otimes \ldots \otimes\left[\begin{array}{ll}
v_{N}^{L} & v_{N}^{H}
\end{array}\right],
$$

To obtain the parameters within the uncertainty hypercube, Monte Carlo method is used to generate a large number ' $M$ ' of independent random parameter sets (within the uncertainty limits from Table 2) for the CFD simulations. The targets obtained from the simulations based on the randomly sampled parameters can be written as:

$$
f=f(v),
$$

where $f$ is the vector of the targets of interest and $v$ is the vector containing one set of the sampled $N$ parameters. Together with the input parameters and targets, the GSA is implemented based on the analysis of variance through the following expansions:

$$
\begin{gathered}
f^{(1)}\left(v_{i}\right)=\sum_{i=1}^{N} \sum_{k=0}^{n} a_{i k} v_{i}^{k}, \\
f^{(2)}\left(v_{i}\right)=\sum_{i=1}^{N} \sum_{k=1}^{n} a_{i k} v_{i}^{k}+\sum_{j=1}^{p} \sum_{s=1}^{n-1} \sum_{k+r \leqslant s(k, r>0)} b_{j k r} v_{u(j, 1)}^{k} v_{u(j, 2)}^{r},
\end{gathered}
$$

where $n$ is the order of the expansion. Equation 5 acts as a "filter" and only parameters whose sensitivity coefficients $\left(S_{i}\right)$ are above a threshold $(0.01$ in this study) are used in the second set of terms in equation 6 . This is represented by $\mathrm{p}$ in equation 6 . The indices " $\mathrm{u}(\mathrm{j}, 1)$ " and " $\mathrm{u}(\mathrm{j}, 2)$ " in equation 6 represent a pair of parameters that are used in the interaction terms based on their $S_{i}$ s. The interaction terms were generated as part of this study but are not shown here since the inclusion of interaction terms did not change 
the ordering at all. Consequently, only the main effects are considered and the interaction terms are omitted in this study. $a_{i k}$ and $b_{j k r}$ indicate the regression coefficients for each parameter. The sensitivity coefficient for each parameter can be calculated based on the ratio of the partial variance and the total variance as shown below:

$$
\begin{gathered}
S_{i}=\sigma_{i}^{2} / \sigma_{t}^{2}, \\
\sigma_{t}^{2}=<f^{2}>-<f>^{2},
\end{gathered}
$$

where the brackets " $<>$ " indicates the mean value over the $M$ simulations. In equation $7, \sigma_{i}^{2}$ stands for the partial variance of the $i^{\text {th }}$ parameter based on the above expansions as shown in equations 5 and 6. Sparse regression technique [28] was used to reduce the sample size while maintaining a good convergence of the results at the same time. In the present study, 60 simulations are run for the $900 \mathrm{~K}$ temperature condition, i.e., $M=60$. To ensure that 60 simulations provided statistically converged results, the extracted targets were divided into two sets, each with 30 runs. GSA applied to results from 30 and 60 simulations showed similar sensitivity coefficients for different variables, suggesting 30 runs are sufficient for the sensitivity analysis. For the $800 \mathrm{~K}$ and $1100 \mathrm{~K}$ ambient conditions, results from 30 simulations are also used for the GSA. Each simulation requires an average of about 75 wall clock hours on 16 processors. Since these are fairly large calculations, it was important to determine apriori the number of simulations necessary to carry out the GSA at each condition. This initial study will be followed by a more exhaustive study to understand uncertainties for other modeling variables also under different conditions. 
It should be noted that for the GSA to provide insightful results, the uncertainty ranges for the variables need to be set carefully. A given variable may show sensitivities that are too high or too low if misguided ranges are used, hence the importance of close collaboration and cross checking between the experimental and modeling efforts is paramount.

\subsection{Modeling methods}

A 3D unsteady Reynold averaged Navier-Stokes (RANS) solver coupled with a multi-flamelet representative interactive flametlet (mRIF) model in CONVERGE CFD code were used for the simulations performed in this study. The simulation approach is well established in our previous publication [9], hence only a brief description is provided here. The liquid spray was treated in a traditional Lagrangian fashion. "Blob" injection model was used by initializing the diameter of liquid droplet as the effective nozzle diameter [29]. The Kelvin Helmholtz (KH) - Rayleigh Taylor (RT) breakup model $[30,31]$ and "no time counter" collision model [32] were adopted for capturing spray breakup and collision processes. Droplet evaporation was modeled using Frossling correlation [33] and the drag on the droplets was modeled using a dynamic drag model [34]. The re-normalization group (RNG) k- $\epsilon$

turbulence model [35] was used. Adaptive mesh refinement (AMR) was also used based on velocity and temperature fields and the minimum cell size was fixed to $0.25 \mathrm{~mm}$ in all calculations, which has been demonstrated to be small enough to obtain grid-convergent results $[9,36]$.

Turbulent combustion was modeled using the mRIF approach [37] by assuming a $\beta$ function for the scalar probability density functions (PDFs). Equations 9 and 10 are the flamelet equations derived from the species conser- 
vation equation by applying a coordinate transformation to mixture fraction space [38]:

$$
\begin{aligned}
\rho \frac{\partial Y_{i}}{\partial t} & =\rho \frac{\chi}{2} \frac{\partial^{2} Y_{i}}{\partial Z^{2}}+\dot{\omega}_{i} \\
\rho \frac{\partial T}{\partial t}-\rho \frac{\chi}{2} \frac{\partial^{2} T}{\partial Z^{2}}= & \rho \frac{\chi}{2 C_{p}}\left[\sum_{i=1}^{n s} \frac{C_{p i}}{L e_{i}} \frac{\partial Y_{i}}{\partial Z}+\frac{\partial C_{p}}{\partial Z}\right] \frac{\partial T}{\partial Z} \\
& +\frac{1}{C_{p}}\left(\frac{\partial p}{\partial t}-\sum_{i=1}^{n s} \dot{\omega}_{i} h_{i}\right)
\end{aligned}
$$

In the above, $Y_{i}$ and $\mathrm{T}$ are the $i^{t h}$ species mass fraction and temperature, respectively. $\mathrm{Z}$ is mixture fraction provided by the CFD solver, $\chi$ is the scalar dissipation rate as a function of $\mathrm{Z}$ and $\dot{\omega}_{i}$ is the reaction source term. In solving the flamelet equations, the domain-averaged stoichiometric scalar dissipation rate is not representative of the values in the whole domain. To take into consideration of this effect, multiple flamelets were used with each one accounting for a certain fraction of the injected fuel mass. In this case, 16 flamelets were generated and equally distributed based on the injection duration. Further details about the mRIF implementation can be found in authors previous publication [9].

A 106-specie (420 reactions) chemical kinetic mechanism [6] for n-dodecane was used in all the simulations, which was developed from a detailed mechanism consisting of 2885 species and 11754 reactions $[39,40]$. This reduced mechanism has been validated under many conditions against the ECN dataset by the authors and other researchers $[9,10]$. The mechanism appears to provide adequate ignition and flame lift-off length predictions for the baseline conditions $(900 \mathrm{~K})$ and for ambient temperature variations [9]. Figure 1 shows the $0 \mathrm{D}$ validations of ignition delay between the reduced and the de- 
tailed mechanisms at different conditions. One can notice that the agreement is really good for the reduced mechanism compared to the detailed one at different equivalence ratios and ambient temperatures. However, the mechanism has not been evaluated in the presence of minor species for different oxygen concentrations of interest in 3D simulations, although 0D calculated results suggest the significance of minor species $[7,15,23]$. The authors acknowledge this shortcoming; however, further mechanism development is beyond the scope of this study. The production and oxidation of soot was modeled using a Hiroyasu model [41].

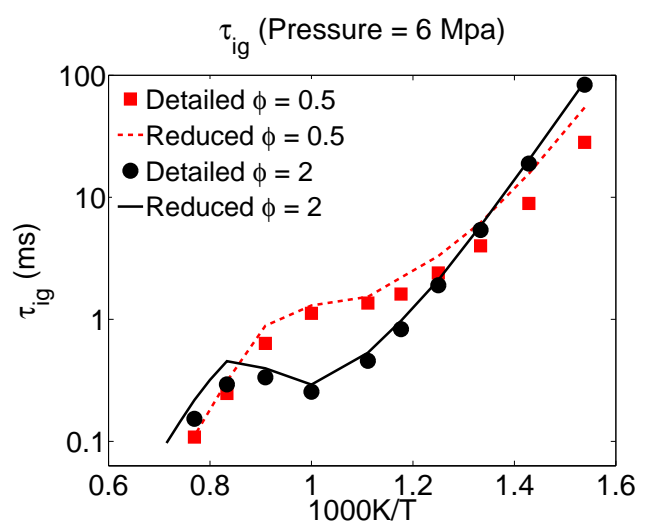

Figure 1: Comparison of ignition delays from reduced and detailed mechanisms for $\mathrm{n}$ dodecane at $\mathrm{phi}=0.5$ and 2 from $0 \mathrm{D}$ homogeneous reactor simulations.

The simulations performed under various input conditions for different variables of interest provided the data for the targets of interest as a function of the input variables. These results were then input into the GSA tool to understand the sensitivity of various parameters on specific targets of interest. Note that a GSA study of the modeling terms (e.g. spray and turbulence) and their uncertainties can also be performed, as demonstrated 
in Pei et al. [19], but the current study is geared towards the evaluation of experimental sensitivities.

We acknowledge that the GSA method to evaluate boundary condition effects may depend upon the particular models employed. Although the models used in this study may match the trend compared to experiment (see Fig. 2), the GSA approach could be extended to offer guidance about which parameters within the models are most important, as was performed in Ref. [19] to evaluate spray constants, for example. Although model parameters were not included in the GSA iterations for this study because of computational limitations, future GSA work could identify the model parameters of most importance, which combined with the boundary condition sensitivity addressed in this study, would make the modeling even more insightful.

\section{Results and discussion}

The targets include liquid length, vapor penetration length, ignition delay, lift-off length, and soot mass in the domain. The 3D CFD simulation settings were well established in our previous studies [9, 42]. Some representative results are shown here for the sake of completeness. Figure 2 shows the validations of the simulations in the exact nominal conditions (no variation from the target conditions) against available SNL experimental data from the ECN website [1]. The liquid length, ignition delay, and lift-off length were predicted reasonably well across different ambient conditions. Although there are some quantitative differences, the simulations qualitatively capture the experimental trends. 


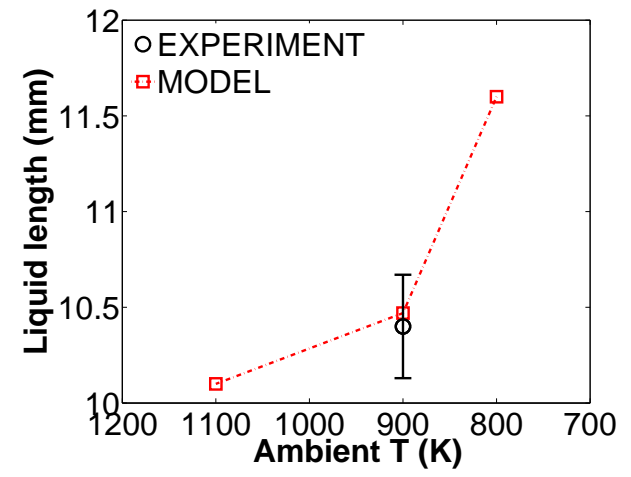

(a) Liquid length

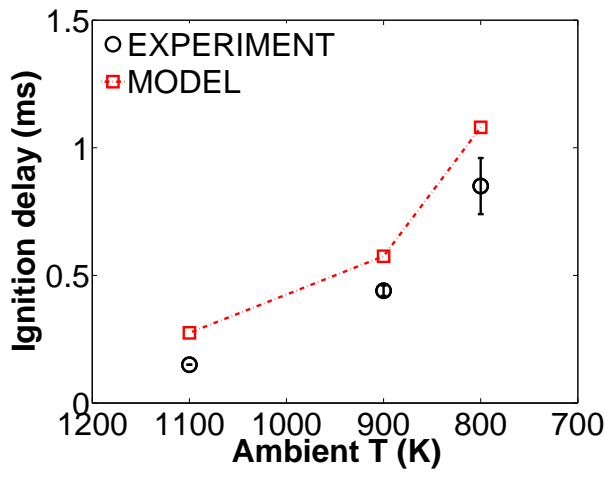

(b) Ignition delay

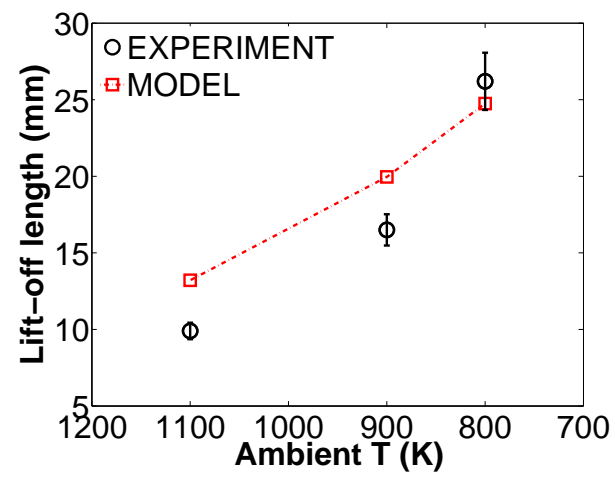

(c) Lift-off length

Figure 2: Validations of (a) liquid length, (b) ignition delay, and (c) lift-off length at different ambient temperature conditions for the CFD simulations. The error bars show the measurement uncertainty.

As an example input for the GSA analysis, the liquid length for 60 simulations at the $900 \mathrm{~K}$ ambient temperature condition is depicted in Fig. 3(a). Liquid length in the simulations was defined as the distance from the nozzle exit to the axial boundary encompassing $99 \%$ of fuel liquid mass in the domain. To extract the liquid length from each simulation, the values were averaged over the quasi-steady state. Despite the rather large number of 
variables and their uncertainty range, the liquid length ranges from $9.8-$ $11.4 \mathrm{~mm}$. The PDF distribution of all the results is shown in Fig. 3(b).

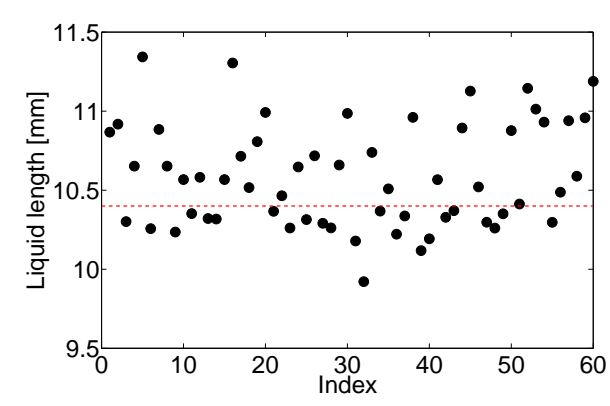

(a) Liquid length

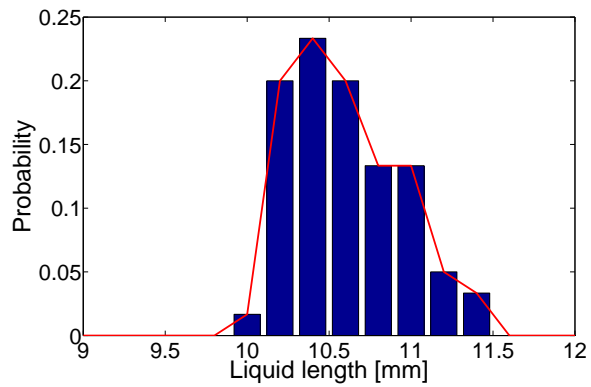

(b) PDF

Figure 3: An example of (a) the liquid length and (b) its PDF at the $900 \mathrm{~K}$ ambient temperature condition over 60 cases. The red dashed line is the experimental results from SNL.

\subsection{Correlations between the targets}

After all the results were extracted from the simulations, a qualitative analysis between different targets was conducted to examine whether there are general trends between certain targets and to gain an initial understanding of the various sensitivities.

Figure 4 reports the computed ignition delay, lift-off length, vapor penetration length, and soot mass. The lift-off length was averaged from 1 to 1.5 $m s$ after start of injection (ASOI) to reduce the statistical error. The vapor penetration length was computed at $1 \mathrm{~ms}$ ASOI, while the soot mass was computed at $1.5 \mathrm{~ms}$ ASOI after more time for spray development but prior to the end of injection. Each quantity was plotted versus liquid length at different ambient temperature conditions to indicate potential relationships 


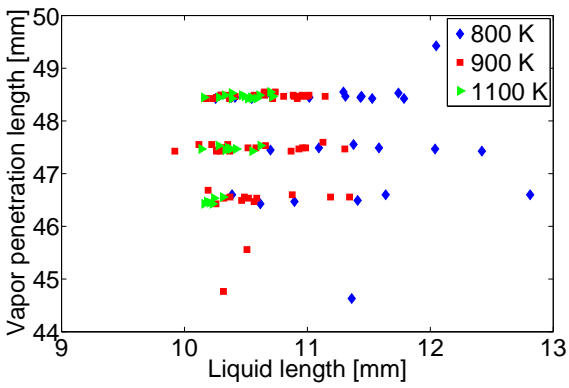

(a) Vapor penetration length vs. liquid length

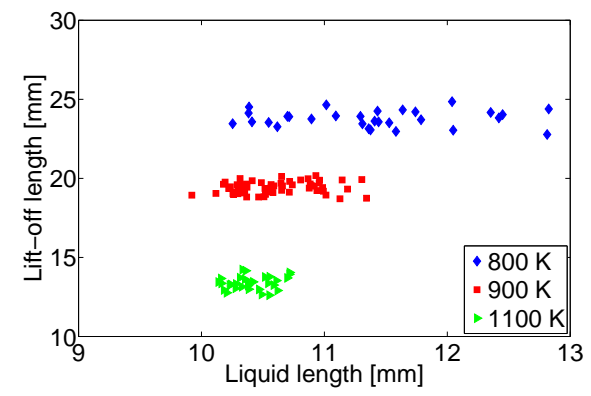

(c) Lift-off length vs. liquid length

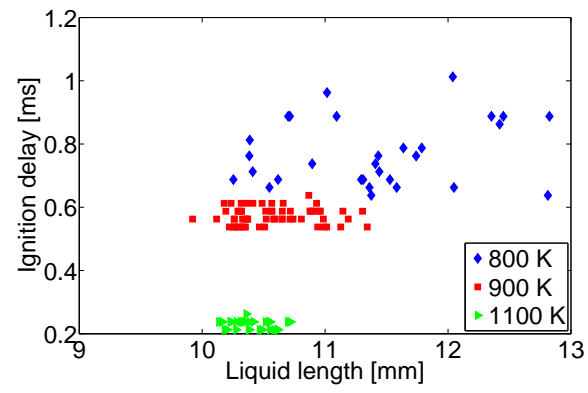

(b) Ignition delay vs. liquid length

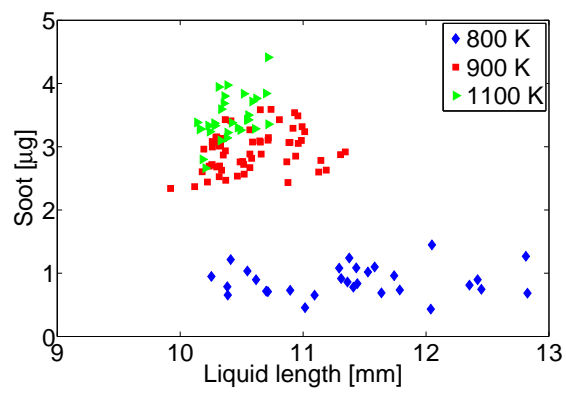

(d) Soot vs. liquid length

Figure 4: (a) Vapor penetration length, (b) ignition delay, (c) lift-off length and (d) soot mass vs. liquid length from simulations under different ambient temperature conditions.

to liquid length. Although not very evident from these plots, higher ambient temperature results in lower liquid penetration lengths. The vapor penetration length indicates how far the vapor phase penetrates and is defined as the length from the nozzle exit to the axial boundary of $1 \%$ of fuel vapor mass fraction. Ignition delay is defined as the time from the start of injection to the time where the maximum rate of maximum temperature rise in the domain is first observed [17]. In simulations, the lift-off length is defined as the axial distance from the nozzle exit to $14 \%$ of maximum $\mathrm{OH}$ mass fraction at 
the quasi-steady state $[7,9]$.

In general, it is difficult to find any correlation between vapor penetration and liquid length. The liquid length is governed by rates of mixing with the hot ambient gas and rate of evaporation. The vapor penetration depends on the momentum exchange between the spray and the ambient gas. Hence, there are many conditions wherein the higher liquid length does not necessarily results in higher vapor penetration length. An example of this is the effect of ambient temperature on these variables. Decreasing the ambient temperature increases the liquid length but does not change the vapor penetration appreciably. The comparison of ignition delay and lift-off length with respect to liquid length also shows no clear correlations. Note that the lengths of vapor penetration and lift-off are downstream of the liquid length [17], even for the highest temperature condition investigated (1100 K) where there are shorter ignition delays and reduced flame lift-off lengths. This results in reduced interactions between the spray and combustion processes. This finding is in agreement with previous studies from both experiments $[4,17,18]$ and simulations $[43,44]$.

Figure 4(d) shows that higher ambient temperature results in increased soot production, which is consistent with experimental findings. In this case, a longer liquid length usually results in higher soot mass in the domain. This trend is more pronounced at higher ambient temperatures where the lift-off lengths are shorter. But at the lower ambient temperature condition of 800 $\mathrm{K}$, the correlation between soot mass and liquid length is weak. Overall, this first analysis of results suggest no clear correlation between liquid length and vapor penetration length, ignition delay, or flame lift-off length, but 
the correlation with soot mass and liquid length suggests further review of possible causes.

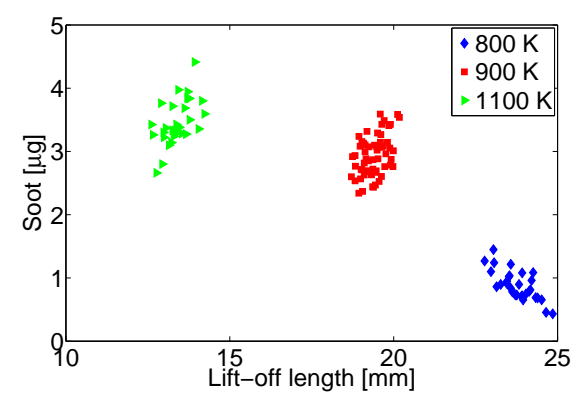

Figure 5: Soot mass vs. lift-off length from simulations at different ambient temperatures.

The soot mass in the domain versus lift-off length is shown in Fig. 5. At the $800 \mathrm{~K}$ ambient temperature condition, a longer lift-off length results in a lower amount of soot mass in the domain, consistent with previous experimental findings $[45,46]$. However, at higher ambient temperatures the trend is reversed, since higher lift-off length seems to result in higher soot mass in the domain. This inconsistency may suggest that the factors affecting lift-off length and soot are different for different ambient conditions. This aspect will be examined in detail later.

Figure 6 plots lift-off length versus ignition delay for the three ambient temperature conditions for both experimental data and computed results. The black ellipse in Fig. 6 marks the measured data from different facilities at the nominal ambient $900 \mathrm{~K}$ condition. The experimental data shows that a longer ignition delay results in higher lift-off length. This trend is also true for the small region around $900 \mathrm{~K}$, although there are a couple of outliers. Simulations can capture this trend when considering both the temperature sweeps and calculations at a specific ambient temperature condition. The 


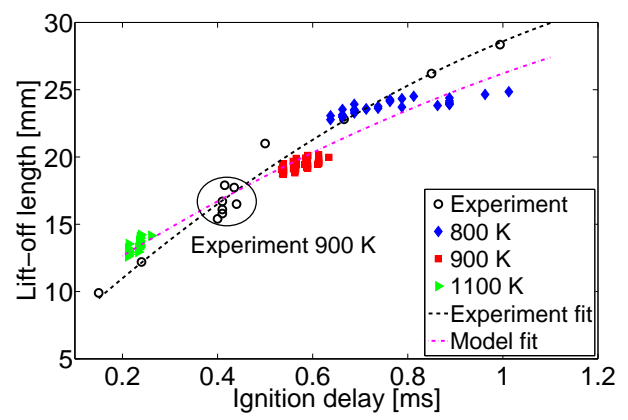

Figure 6: Lift-off length vs. ignition delay from experiments and simulations. The black and pink lines are polynomial fits for experiments and simulations, respectively.

two dashed lines represent the polynomial fits of the experimental data and calculated results, respectively. The trend of the two fits is similar although the slopes are slightly different, which suggests that the sensitivity of lift-off length with respect to ignition delay is marginally different between experiments and simulations.

\subsection{Global sensitivity analysis}

After establishing the correlations between different targets, GSA was performed on each target at different ambient temperature conditions, in order to identify the important parameters influencing each target.

Liquid length. The sensitivity coefficients of the different variables for liquid length at different ambient conditions are reported in Fig. 7. Overall, the fuel temperature is the most dominant factor influencing the liquid length at different ambient temperatures. This is not surprising because of the large uncertainty for fuel temperature in different experimental facilities (shown in Table 2). The sensitivity coefficients for the ambient temperature are also quite small, suggesting that the uncertainty in ambient temperature has a 
minimal influence on liquid length at the lower temperature conditions. This does not mean that the ambient temperature has no effect on the liquid length, but suggests that the effect is rather small compared to the large uncertainty in the fuel temperature.

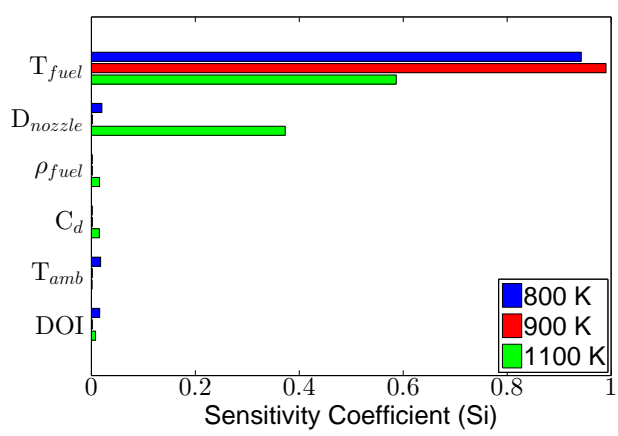

Figure 7: Sensitivity coefficients of different variables for liquid length at different ambient temperatures.

Nozzle diameter is also important to liquid length, especially for the higher ambient temperature $(1100 \mathrm{~K})$ condition. At lower ambient temperatures the evaporation rate is significantly influenced by the fuel temperature. The increase in ambient temperature enhances the evaporation rate further. Since the blob injection model uses the effective nozzle diameter as the initial liquid droplet size issuing into the combustion chamber, the uncertainty in nozzle diameter seems to play a prominent role at higher ambient temperature conditions.

With the identification of the strong effect of fuel temperature on liquid length, we can compare our results to past expectations based on experiment and other modeling. The solid red line in Fig. 8 represents the regression fit of the liquid lengths (green markers) with respect to the fuel temperature for the 60 simulations at the $900 \mathrm{~K}$ condition. At a certain fuel temperature, 


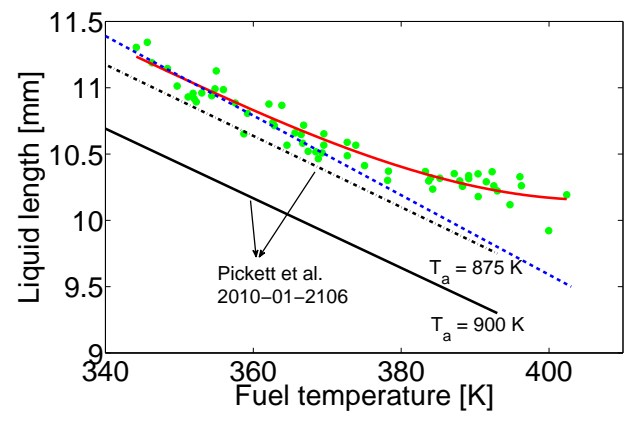

Figure 8: Regression fit of the liquid length versus fuel temperature at $900 \mathrm{~K}$. The green markers are the liquid length predictions from simulations and the red curve is the regression fit. The dashed blue line is the estimation from reference [15] and the two black lines are from reference [2] at different ambient temperatures.

the variation of the liquid length is due to the variations of all other input variables. The dashed blue line is the estimation from Meijer et al. [15] and the two black lines are from Pickett et al. [2], both obtained from Siebers' model [47]. The regression fit trend compares well with the lines reported in the literature. It is interesting to note that the curvature of the fitting curve becomes small when the fuel temperature increases to about $390 \mathrm{~K}$. This may be explained by the evaporation rate of the liquid fuel reaching a threshold when the fuel temperature is high. It can be seen in Fig. 8 that both fuel and ambient temperature affect liquid fuel evaporation rate. From the modeling point of view, Frossling correlation was used to calculate the rate of change of droplet size, which is proportional to the liquid vapor mass diffusivity $D$ and inversely proportional to the liquid density. Higher ambient temperature will lead to larger $D$, and higher fuel temperature will lead to lower liquid density, both result in faster evaporation rate. 
Vapor penetration length. The sensitivity coefficients of different parameters for the vapor penetration length target at $1 \mathrm{~ms}$ for the three ambient temperatures are shown in Fig. 9. The initial ambient gas velocity fluctuation (i.e., the initial turbulence intensity) is the most sensitive parameter influencing the vapor penetration length at all ambient conditions. This finding is especially important because at present, the experimental data on initial velocity is quite scarce, and it serves as a motivation for more accurate measurement of this initial condition. The nozzle diameter is another important parameter that consistently appears for the three conditions. Malbec et al. [18] reported 5\% dispersion (considered within the uncertainty range) of vapor penetration length measurement from a set of "identical"-specification ECN Spray A injectors. Since the experiments were performed in the same combustion chamber, the variation in nozzle diameter due to manufacturing tolerances can explain these vapor penetration length differences. The GSA study suggests that the small variations in nozzle diameter and initial conditions could lead to differences in the vapor penetration measurements and contribute to the experimental uncertainties. Fuel properties show some sensitivity to the vapor penetration length, also; however, compared to the other two parameters noted above, the sensitivity is smaller.

Ignition delay. Figure 10 shows the sensitivity coefficients of different variables versus ignition delay at different ambient temperatures. Several interesting things can be observed. First, the uncertainty in ambient temperature is an important factor at 800 and $1100 \mathrm{~K}$, while less important at the $900 \mathrm{~K}$ condition. A plausible explanation is negative temperature coefficient (NTC) behavior as shown in Fig. 11. From shock tube experiments [48] and 0D sim- 


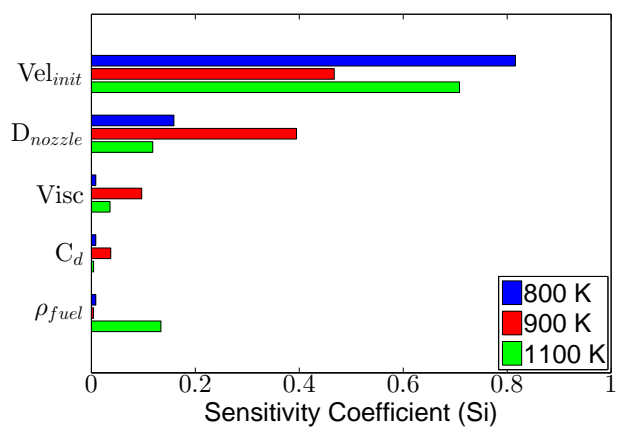

Figure 9: Sensitivity coefficients of different variables versus vapor penetration length at different ambient temperatures.

ulations, the n-dodecane fuel clearly shows NTC behavior, with $900 \mathrm{~K}$ being the point of inflexion. At $800 \mathrm{~K}$ and $1100 \mathrm{~K}$, minor differences in temperature will either increase or decrease the ignition delay. However, at $900 \mathrm{~K}$ minor changes in temperature will only increase the ignition delay. This is perhaps the reason that the uncertainty in ambient temperature is not shown to be sensitive at $900 \mathrm{~K}$. Second, the uncertainty in ambient oxygen concentration is of substantial importance at the $900 \mathrm{~K}$ and $1100 \mathrm{~K}$ conditions, but barely has any influence at the $800 \mathrm{~K}$ condition. This suggests that the ignition at a lower ambient temperature (less reactive) condition is more sensitive to the ambient temperature than the ambient oxygen concentration. However, this could just be an artifact of the reduced mechanism used and the mechanism uncertainty could also be important. Third, the effects of $\mathrm{CO}_{2}$ and $\mathrm{H}_{2} \mathrm{O}$ are not negligible, possibly because of participating third-body reactions. Ambient composition differences between facilities should therefore receive notice and attention. Lastly, the minor species, $\mathrm{OH}$, does play a significant role in the predictions of ignition delay. If $\mathrm{OH}$ specie persists in preburn-type chambers, it may therefore affect ignition. The minor species effect of $\mathrm{OH}$ 
and NO has been studied by Meijer et al. [15] and Pei et al. [7] using current chemical kinetic mechanisms, and both studies suggest that the minor species influence ignition. However, there is no experimental data suggesting the persistence of $\mathrm{OH}$ in preburn chambers, and the chemical kinetic studies do not have veritable proof from experiments demonstrating that small amounts of $\mathrm{OH}$ really do produce the same effect.

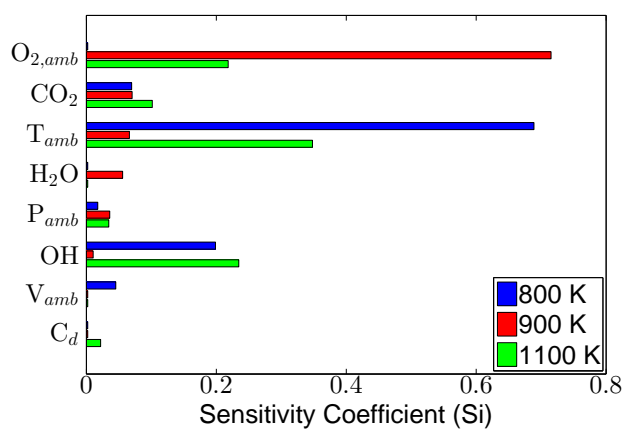

Figure 10: Sensitivity coefficients of different variables versus ignition delay at different ambient temperatures.

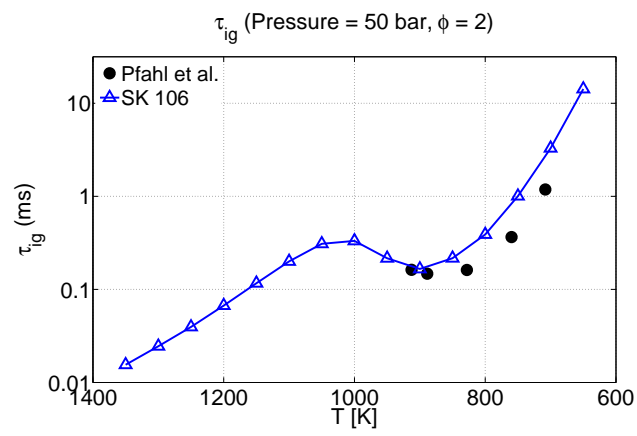

Figure 11: Computed ignition delay of the 106 species mechanism at different ambient temperatures at an ambient pressure of 50 bar and $\phi=2$. The black markers are shock tube experiments from Pfahl et al. [48] and the computed results were calculated using SENKIN [49]. 
It is interesting to note that the fuel temperature does not show up in Fig. 10 although it is the most sensitive parameter for liquid length. This confirms the weak correlation between ignition delay and liquid length under the conditions investigated in this study. Experiments by Payri et al. [4] also support this finding, wherein the differences in fuel temperature were very important for liquid length variations, but of only minor influence on ignition delay as compared to other ambient variables, such as ambient temperature and pressure, etc.

We can evaluate the importance of the most dominant variables on ignition delay compared to past understanding and experiments. Experiments in diesel sprays have shown some success in scaling results with respect to an Arrhenius correlation:

$$
\tau_{i g}=A \exp \left(E / R T_{a m b}\right)\left[O_{2, a m b}\right]^{n}
$$

where $\mathrm{A}$ is the pre-exponential constant, $\mathrm{E}$ is activation energy, and $\mathrm{R}$ is the universal gas constant. $\mathrm{T}_{a m b}$ and $\mathrm{O}_{2, a m b}$ are the ambient temperature and oxygen concentrations, respectively, and can explicitly affect the ignition delay. However, the correlation does not account for the influence of other parameters such as minor species on ignition delay. This also motivates the need for developing more advanced correlations for ignition delay accounting for minor species effects.

A regression fit of ignition delay with respect to the ambient oxygen at $900 \mathrm{~K}$ ambient temperature is shown in Figure 12. The ignition delay is smaller when the ambient oxygen is higher, which is expected. At a given oxygen concentration, the difference in ignition delay is due to the variation in other parameters. 


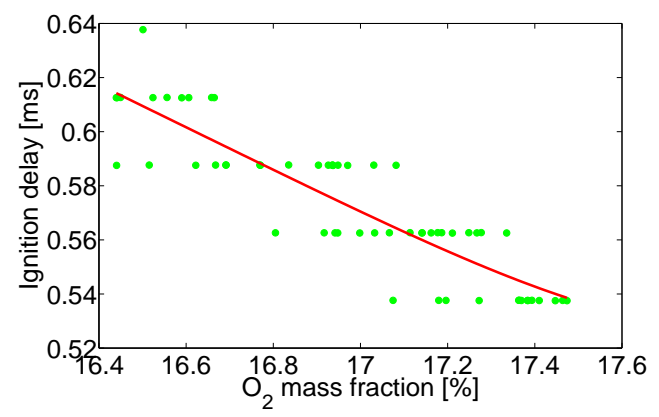

Figure 12: Regression fit of the ignition delay versus $\mathrm{O}_{2}$ mass fraction at $900 \mathrm{~K}$. The green markers are the ignition delay predictions from simulations and the red curve is the regression fit.

Lift-off length. Figure 13 reports the sensitivity coefficients of different variables versus the lift-off length at three different ambient temperature conditions. As expected, similar to what was found for the sensitivity analysis of ignition delay, there is a good correlation between lift-off length and ignition delay as shown in Fig. 6,1) the ambient temperature is important for the 800 and $1100 \mathrm{~K}$ conditions, but less crucial for $900 \mathrm{~K}, 2)$ the ambient oxygen condition is less sensitive at the lower ambient temperature condition, and 3) the ambient composition is also an influence. Compared to ignition delay, the sensitivity to the nozzle diameter on lift-off length is more significant, and it is important for all temperatures.

In order to demonstrate the efficacy of the GSA, the experimental liftoff lengths from SNL and CMT are plotted in Fig. 14. Differences can be noticed for the experimental data from these two facilities, especially at lower ambient temperature conditions. Figure 13 shows that lift-off length at $800 \mathrm{~K}$ is most sensitive to ambient temperature, nozzle diameter, and minor species. Comparing these parameters for SNL and CMT, we find that indeed, there 


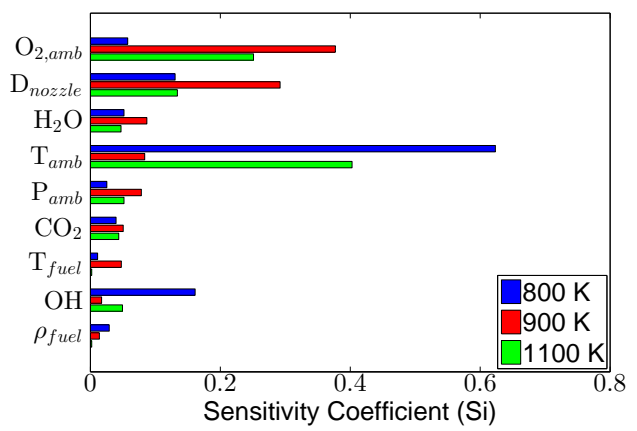

Figure 13: Sensitivity coefficients of different variables versus lift-off length at different ambient temperatures.

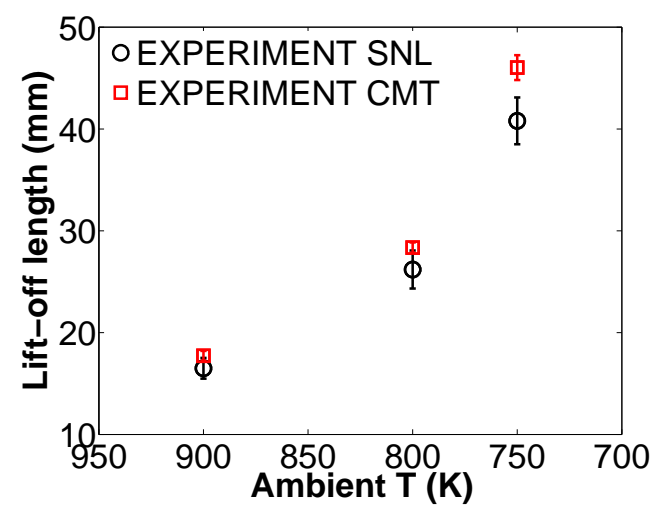

Figure 14: Experimental lift-off length comparison between SNL and CMT at different ambient temperatures.

are appreciable differences. For example, the mean ambient core temperature (800.8 K for SNL and $810.8 \mathrm{~K}$ for CMT), nozzle diameter (83.7 $\mu m$ for SNL and $89.4 \mu \mathrm{m}$ for CMT) and minor species (with minor species for SNL and without minor species for $\mathrm{CMT}$ ), these differences are the prime reasons for the lift-off length differences. This information can be used to guide experimentalists to better control these boundary conditions in the future.

Once again, we can compare the expectations for lift-off length senstivity 
against past experience. Siebers et al. [50] proposed a power-law relationship for the spray flame lift-off length $\mathrm{H}_{l o l}$ based on extensive measurements, as shown in Equation 12:

$$
H_{l o l}=C T_{a m b}^{-3.74} \rho_{a m b}^{-0.85} D_{n o z z l e}^{0.34} U Z_{s t}^{-1}
$$

where $C$ is a constant and $\rho_{a m b}$ is the ambient density. $U$ is the injection velocity and $\mathrm{Z}_{s t}$ is the stoichiometric mixture fraction, which correlates with the ambient oxygen level. In agreement with this equation, we find that all the variables on the right-hand side are reflected as significant in the GSA results shown in Fig. 13. For example, $\mathrm{Z}_{s t}$ represents the level of ambient oxygen, which is inversely proportional to the lift-off length. This is supported by Fig. 15(a), which shows the regression fit of lift-off length to the ambient oxygen level where higher ambient $\mathrm{O}_{2}$ leads to lower lift-off length. Also, the increasing lift-off length with nozzle diameter from Equation 12 is consistent with Fig. 15(b), showing the regression fit of lift-off length to the nozzle diameter at the $900 \mathrm{~K}$ condition. The influence of ambient temperature, ambient oxygen concentration and nozzle diameter on lift-off length across a large range of conditions is well established in Siebers et al. [50]. The current study shows that the responses of lift-off length to these parameters even in a narrow uncertainty range is consistent with these previous findings.

Figure 16 depicts the equivalence ratio along the spray axis for the cases with shortest and longest lift-off length, and also three random cases at the $900 \mathrm{~K}$ ambient temperature condition. The solid markers represent the equivalence ratio at the lift-off locations on the centerline, and hollow markers are the values at the lift-off locations, respectively. Although the lift-off locations span 18.7 to $20.2 \mathrm{~mm}$, it is interesting that the centerline equivalence ratios 


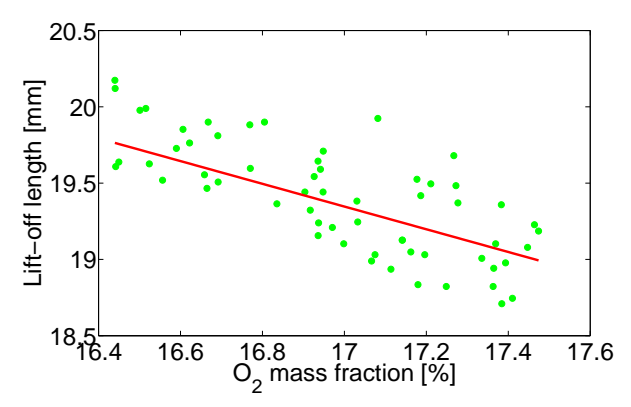

(a) $\mathrm{O}_{2}$ mass fraction

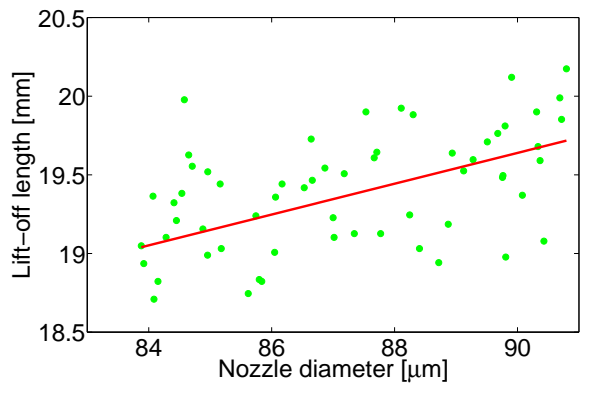

(b) Nozzle diameter

Figure 15: Regression fit of the lift-off length versus the (a) $\mathrm{O}_{2}$ mass fraction and (b) nozzle diameter at $900 \mathrm{~K}$. The green markers are the lift-off length predictions from simulations and the red curve is the regression fit.

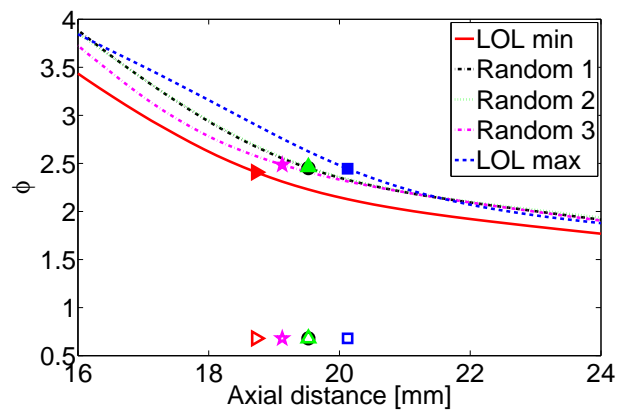

Figure 16: Comparison of $\phi$ on the centerline for the two cases with shortest and longest lift-off lengths, and three random cases at $900 \mathrm{~K}$. Solid markers represent the equivalence ratio at the lift-off locations on the centerline, and hollow markers are the values at the lift-off locations, respectively.

at the lift-off locations are quite similar and close to 2.5 , while the values at lift-off locations are close to 0.68. This may suggest similar scalar gradients in the vicinity of the lift-off location, indicating that turbulent diffusion may play a role in the flame stabilization mechanism. The flame stabilization mechanism analysis for Spray A by Pei et al. [8] suggested that flame sta- 
bilization was autoignition-controlled, but moderated by turbulent diffusion and support the findings shown in Fig. 16.

Soot. After investigating the influence of different variables on spray and combustion characteristics, this section discusses the uncertainty of different variables on soot mass in the domain. Figure 17 presents the sensitivity coefficients of different variables on soot mass at different ambient temperature conditions. The total soot mass in the domain at $1.5 \mathrm{~ms}$ ASOI is used as the soot indicator. From previous experiments, it is known that there is no soot at $800 \mathrm{~K}$. The simulations show that soot at $800 \mathrm{~K}$ is about $30 \%$ of the value at $900 \mathrm{~K}$. We believe that at $800 \mathrm{~K}$, the simulations predict soot because of the rather simple Hiroyasu soot model employed. Nevertheless, the soot trends predicted by the simulations are expected to be reasonable.

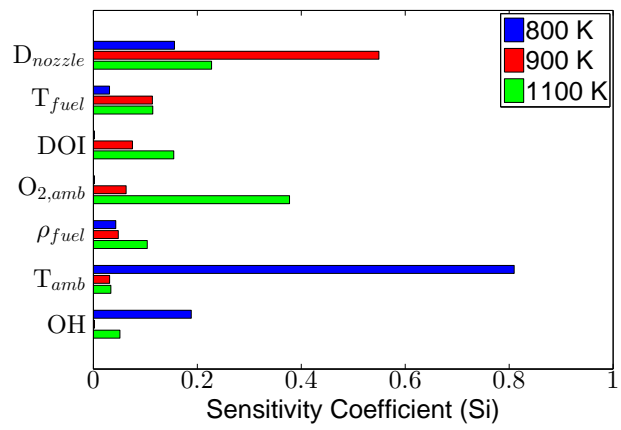

Figure 17: Sensitivity coefficients of different variables versus soot mass in the domain, at different ambient temperatures.

One expected effect is the high sensitivity of ambient temperature, particularly at the low-temperature condition of $800 \mathrm{~K}$. Ambient temperature uncertainty was the single most sensitive coefficient for ignition delay and flame lift-off length and its importance persists for soot. But other vari- 
ables that profoundly affect soot are somewhat different than the spray and combustion indicators already discussed. First, the nozzle diameter has the most significant influence on soot mass in the domain when considering all ambient temperatures. Second, the fuel temperature uncertainty appears to be important to a certain extent at least for the higher temperature cases (900 and $1100 \mathrm{~K}$ ), unlike ignition delay or lift-off length. Third, the soot mass in the domain progressively becomes more sensitive to the uncertainty in ambient $\mathrm{O}_{2}$ concentration as ambient temperature increases.

Finally, the regression fit of soot versus the nozzle diameter is shown in Figure 18. It is clear that a larger nozzle diameter results in higher soot mass in the domain, which is consistent with the literature [51]. For a given nozzle diameter, the variation in lift-off length is due to the variations in other parameters in the simulation.

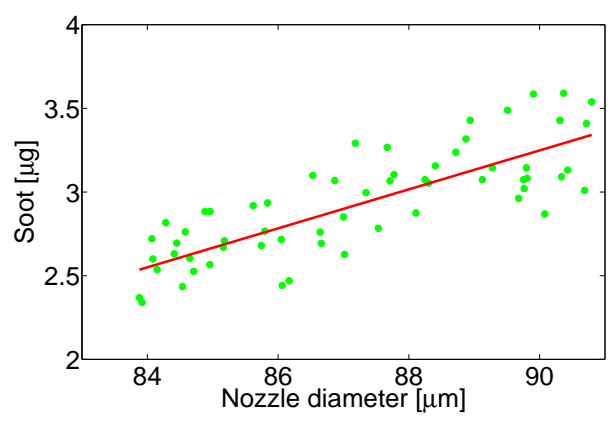

Figure 18: Regression fit of soot versus nozzle diameter at $900 \mathrm{~K}$. The green markers are the soot mass predictions from simulations and the red curve is the regression fit.

\section{Summary and conclusions}

To create better standardization among researchers in the ECN community, a GSA study was conducted on ECN Spray A conditions across various 
institutions to understand the differences in the boundary, initial, and injection conditions. A list of experimental conditions with uncertainty ranges was identified and these were simultaneously varied across the uncertainty range as inputs in the CFD simulations. The simulation outputs were then analyzed using a GSA method to determine the sensitivity of five targets of interest including liquid and vapor penetration lengths, ignition delay, lift-off length, and soot mass in the domain. Three different ambient temperatures were considered in the study. Some key observations are noted below:

- Liquid length does not correlate strongly with either ignition delay or flame lift-off length. This demonstrates that perhaps, spray processes have a rather diminished influence on ignition and combustion characteristics. While this may be true for the conditions investigated (since the lift-off length is appreciably longer than liquid length), liquid length significantly influences the total soot mass in the domain. This suggests that spray processes are critical for soot emissions.

- Small uncertainties in the initial turbulence level and nozzle diameter have a profound influence on the vapor distribution. This observation motivates the need for higher fidelity measurements of this initial condition and tighter manufacturing tolerances for nozzle orifices.

- The uncertainty in ambient conditions and oxygen concentration are expected to influence the ignition delay, and the existing ignition delay correlations can capture this effect. The GSA shows that uncertainty in minor species concentrations can also influence ignition delay. Hence, ignition delay correlations need to account for the minor species effects. 
- Variables sensitive to ignition delay also show similar sensitivity to flame lift-off length. Longer ignition delay results in higher lift-off lengths and lower soot mass in the domain which is consistent with previous findings in literature. At the $800 \mathrm{~K}$ and $1100 \mathrm{~K}$ conditions, the ambient temperature was found to be more sensitive, while the ambient oxygen concentration was very sensitive for the ignition delay and lift-off length at the $900 \mathrm{~K}$ condition.

- Fuel temperature showed profound sensitivity towards liquid spray and soot characteristics, but a rather small effect on ignition and combustion characteristics. The uncertainty range was set to be quite high for this parameter since experimental measurements were not available. With the availability of experimental data, tighter tolerances could be set for this variable.

- For the GSA to provide insightful results, the uncertainty ranges for the variables need to be set carefully. A given variable may not be sensitive for a certain target; nevertheless, if the uncertainty range is set too high, it may show up as sensitive, thus misleading the analysis.

This study demonstrates the need for rigorous GSA of experimental boundary conditions and provides unique insights on the influence of different variables on targets of interest. Future studies will also focus on the uncertainties related to chemical kinetic mechanisms, spray and combustion modeling parameters. 


\section{Acknowledgments}

The submitted manuscript has been created by UChicago Argonne, LLC, Operator of Argonne National Laboratory (Argonne). Argonne, a U.S. Department of Energy Office of Science laboratory, is operated under Contract No. DE-AC02- 06CH11357. The U.S. Government retains for itself, and others acting on its behalf, a paid-up nonexclusive, irrevocable worldwide license in said article to reproduce, prepare derivative works, distribute copies to the public, and perform publicly and display publicly, by or on behalf of the Government.

This research was funded by DOE's Office of Vehicle Technologies, Office of Energy Efficiency and Renewable Energy under Contract No. DE-AC0206CH11357. The authors wish to thank Gurpreet Singh and Leo Breton, program managers at DOE, for their support. This work was also supported by the U. S. Department of Energy, Office of Basic Energy Sciences, Division of Chemical Sciences, Geosciences, and Biosciences, under Contract No. DEAC02-06CH11357.

We gratefully acknowledge the computing resources provided on Fusion, a computing cluster operated by the Laboratory Computing Resource Center at Argonne National Laboratory. The authors would also thank Dr. Julien L. Manin and Dr. Jose M. Garcia for the useful discussions.

\section{References}

[1] L. Pickett, G. Bruneaux, R. Payri, Engine Combustion Network (2014) http://www.ca.sandia.gov/ecn. 
[2] L. M. Pickett, C. L. Genzale, G. Bruneaux, L.-M. Malbec, L. Hermant, C. Christiansen, J. Schramm, SAE Int. J. Engines 3 (2010) 156-181.

[3] L. M. Pickett, J. Manin, C. L. Genzale, D. L. Siebers, M. P. Musculus, C. A. Idicheria, SAE Int. J. Engines 4 (2011) 764-799.

[4] R. Payri, J. M. García-Oliver, M. Bardi, J. Manin, Appl. Therm. Eng. 35 (2012) 185-195.

[5] J. Benajes, R. Payri, M. Bardi, P. Martí-Aldaraví, Appl. Therm. Eng. 58 (2013) 554-563.

[6] Z. Luo, S. Som, S. M. Sarathy, M. Plomer, W. J. Pitz, D. E. Longman, T. Lu, Combust. Theory Model. 18 (2014) 187-203.

[7] Y. Pei, E. R. Hawkes, S. Kook, G. M. Goldin, T. Lu, Combust. Flame (2015). doi:10.1016/j.combustflame.2014.12.019.

[8] Y. Pei, Transported PDF Modelling of Spray Combustion at Practical Diesel Engine Conditions, Ph.D. thesis, The University of New South Wales, Sydney, Australia, 2013.

[9] P. Kundu, Y. Pei, M. Wang, M. Raju, S. Som, Atomization Sprays 24 (2014) 779-800.

[10] G. D’Errico, T. Lucchini, F. Contino, M. Jangi, X.-S. Bai, Combust. Theory Model. 18 (2013) 65-88.

[11] S. Bhattacharjee, D. C. Haworth, Combust. Flame 160 (2013) 20832102. 
[12] Y. Pei, P. Kundu, G. M. Goldin, S. Som, SAE paper (2015) 20159036, submitted.

[13] E. Hawkes, Y. Pei, S. Kook, S. Sibendu, Proc. Australian Combust. Symp., AU., (2013).

[14] M. Chishty, Y. Pei, E. Hawkes, M. Bolla, S. Kook, Proc. Australasian Fluid Mech. Conf., AU., (2014).

[15] M. Meijer, B. Somers, J. Johnson, J. Naber, S.-Y. Lee, L. M. Malbec, G. Bruneaux, L. M. Pickett, M. Bardi, R. Payri, Atomization Sprays 22 (2012) 777-806.

[16] M. Bardi, R. Payri, L. M. Malbec, G. Bruneaux, L. M. Pickett, J. Manin, T. Bazyn, C. Genzale, Atomization Sprays 22 (2012) 807-842.

[17] E. Hawkes, Y. Pei, C. Angelberger, M. Bardi, ECN2 proceedings, ECN2: Ignition and Lift-off Length (2012). URL: http://www .ca. sandia.gov/ ecn/workshop/ECN2 . php.

[18] L.-M. Malbec, J. Egúsquiza, G. Bruneaux, M. Meijer, SAE Int. J. Engines 6 (2013) 1642-1660.

[19] Y. Pei, R. Shan, S. Som, T. Lu, D. Longman, M. J. Davis, SAE paper (2014) 2014-01-1117.

[20] D. Zhou, M. J. Davis, R. T. Skodje, J. Phys. Chem. A 117 (2013) 35693584 .

[21] J. J. Scire, F. L. Dryer, R. A. Yetter, Int. J. Chem. Kinet. 33 (2001) 784-802. 
[22] J. Zádor, I. G. Zsély, T. Turányi, Reliab. Eng. Syst. Safe. 91 (2006) 1232-1240.

[23] J. E. Nesbitt, S. E. Johnson, L. M. Pickett, D. L. Siebers, S.-Y. Lee, J. D. Naber, Energy Fuels 25 (2011) 926-936.

[24] D. P. Schmidt, ECN3 proceedings, ECN3: Internal flow (2014) http://www.ca.sandia.gov/ecn/workshop/ECN2.php. URL: http:// www. ca. sandia.gov/ecn/workshop/ECN2 . php.

[25] E. W. Lemmon, M. L. Huber, Energy Fuels 18 (2004) 960-967.

[26] F. Contino, J.-B. Masurier, F. Foucher, T. Lucchini, G. DErrico, P. Dagaut, Fuel 137 (2014) 179-184.

[27] D. Zhou, R. T. Skodje, W. Liu, M. J. Davis, 8th U.S. National Combust. Meeting May 19-22 (2013).

[28] T. Hastie, R. Tibshirani, J. Friedman, T. Hastie, J. Friedman, R. Tibshirani, The elements of statistical learning, volume 2, Springer, 2009.

[29] R. Reitz, R. Diwakar, SAE paper (1987) 870598.

[30] R. D. Reitz, Atomisation Spray Technol. 3 (1987) 309-337.

[31] M. A. Patterson, R. D. Reitz, SAE paper (1998) 980131.

[32] D. P. Schmidt, C. Rutland, J. Comput. Phys. 164 (2000) 62-80.

[33] N. Frossling, N.A.C.A. 168 (1956) AD-B189.

[34] A. B. Liu, D. Mather, R. D. Reitz, SAE paper (1993) 930072. 
[35] Z. Han, R. D. Reitz, Combust. Sci. Technol. 106 (1995) 267-295.

[36] P. Senecal, E. Pomraning, K. Richards, S. Som, J. Energy Resour. Technol. 136 (2014) 012204.

[37] H. Pitsch, M. Chen, N. Peters, Proc. Combust. Inst. 27 (1998) 10571064.

[38] N. Peters, Progress in energy and combustion science 10 (1984) 319-339.

[39] C. K. Westbrook, W. J. Pitz, O. Herbinet, H. J. Curran, E. J. Silke, Combustion and Flame 156 (2009) 181-199.

[40] S. Sarathy, C. Westbrook, M. Mehl, W. Pitz, C. Togbe, P. Dagaut, H. Wang, M. Oehlschlaeger, U. Niemann, K. Seshadri, et al., Combustion and flame 158 (2011) 2338-2357.

[41] H. Hiroyasu, T. Kadota, SAE paper (1976) 760129.

[42] Q. Xue, S. Som, P. K. Senecal, E. Pomraning, Atomization Sprays 23 (2013) 925-955.

[43] Y. Pei, E. R. Hawkes, S. Kook, Flow, Turbul. Combust. 91 (2013) 249280.

[44] Y. Pei, E. R. Hawkes, S. Kook, Proc. Combust. Inst. 34 (2013) 30393047.

[45] J. Manin, L. M. Pickett, S. A. Skeen, SAE Int. J. Engines 6 (2013) $1908-1921$.

[46] L. M. Pickett, D. L. Siebers, Combust. Flame 138 (2004) 114-135. 
[47] D. Siebers, SAE paper (1999) 1999-01-0528.

[48] U. Pfahl, K. Fieweger, G. Adomeit, Proc. Combust. Inst. 26 (1996) $781-789$.

[49] R. Kee, F. Rupley, J. Miller, M. Coltrin, J. Grcar, E. Meeks, H. Moffat, A. Lutz, G. Dixon-Lewis, M. Smooke, CHEMKIN Collection, Release 3.6 (2000) Reaction Design Inc., San Diego, CA.

[50] D. Siebers, B. Higgins, L. Pickett, SAE paper (2002) 2002-01-0890.

[51] L. M. Pickett, D. L. Siebers, J. Eng. Gas Turb. Power 127 (2005) 187196. 